\title{
Anisotropy effects during dwell-fatigue caused by $\delta$-phase orientation in forged Inconel 718
}

\author{
Jonas Saarimäki ${ }^{a, *}$, Magnus HÃúrnqvist Colliander ${ }^{\mathrm{b}, \mathrm{c}}$, Johan J. Moverare ${ }^{\mathrm{a}}$ \\ ${ }^{a}$ Division of Engineering Materials, Department of Management and Engineering, Linköping \\ University, SE-58183 Linköping, Sweden \\ ${ }^{b}$ Department of Applied Physics, Chalmers University of Technology, SE-41296 Göteborg, Sweden \\ ${ }^{c}$ GKN Aerospace Engine Systems, R\&T Centre, SE-46181 Trollhättan, Sweden
}

\begin{abstract}
Inconel 718 is a commonly used superalloy for turbine discs in the gas turbine industry. Turbine discs are often subjected to dwell-fatigue as a result of long constant load cycles. The effect of anisotropy on dwell-fatigue cracking in forged turbine discs have not yet been thoroughly investigated. Crack propagation behaviour was characterised using compact tension $(\mathrm{CT})$ samples cut in different orientations from a real turbine disc forging. Samples were also cut in two different thicknesses in order to investigate the influence of plane strain and plane stress condition on the crack propagation rates. The samples were subjected to dwell-fatigue tests at $550{ }^{\circ} \mathrm{C}$ with $90 \mathrm{~s}$ or $2160 \mathrm{~s}$ dwell-times at maximum load. Microstructure characterisation was done using scanning electron microscopy (SEM) techniques such as electron channelling contrast imaging (ECCI), electron backscatter diffraction (EBSD), and light optical microscopy (LOM). The forged alloy exhibits strong anisotropic behaviour caused by the non-random $\delta$-phase orientation. When $\delta$-phases were oriented perpendicular compared to parallel to the loading direction, the crack growth rates were approximately ten times faster. Crack growth occurred preferably in the interface
\end{abstract}

\footnotetext{
*jonas.saarimaki@liu.se +4613281193
} 
between the $\gamma$-matrix and the $\delta$-phase.

Keywords: Anisotropy, Nickel-based superalloys, Fatigue, Mechanical characterisation, Scanning electron microscopy

\section{Introduction}

Superalloys show a positive combination of mechanical properties and corrosion resistance, which is why they are used in some of the worlds most aggressive working conditions i.e., the hot-section of gas turbines and aero engines. These harsh conditions are detrimental to the alloy in the form of e.g., fatigue, creep, and oxidation, which all, can lead to catastrophic failure.

The polycrystalline Ni-Fe-base superalloy Inconel 718 belongs to the more commonly used superalloys available on the market. It derives its strength from solid solution alloying elements, gamma prime $\gamma^{\prime}$ and gamma double prime $\gamma^{\prime \prime}$ precipitates.

Inconel 718 is recurrently used for high temperature components subjected to cyclic loading, especially when the risk for fatigue and creep deformation is evident, such as turbine discs. Turbine discs can be subjected to temperatures up to $\sim 550{ }^{\circ} \mathrm{C}$ in land-based gas turbines and up to $\sim 700{ }^{\circ} \mathrm{C}$ in aero engines at which the mechanical properties start to degrade considerably [1].

Components subjected to combinations of high temperatures up to $700{ }^{\circ} \mathrm{C}$ and sustained periods of high tensile loads can experience an accelerated crack growth due to the dwell-times. Not only dwell-times effect crack growth but so does environmental aspects. The influence of an oxidising environment has long been recognised to be the main reason for accelerated crack growth rates [2-4]. In addition an accelerated crack growth rate is often accompanied by a change in crack growth mechanism from transgranular to intergranular crack paths. This is particularly true for fine grained and high strength alloys [2-5]. For lower strength alloys, the effects of creep 
deformation should be considered carefully since stress relaxation ahead of the crack tip will lower the mechanical driving forces for crack growth. If the degree of crack tip creep deformation is significant, the local creep deformation blunts the crack tip, which can cause a reduction of the crack growth rates [6-8]. A similar retardation effect has also been observed when an overload is applied prior to the dwell-time $[9,10]$.

A number of different microstructural and chemical features influence crack propagation behaviour of Inconel 718, such as; grain size [5, 11], the presence of serrated grain boundaries [11], the orientation of special coincident site lattice (CSL) grain boundaries [12], the Niobium content [13] and the presence of different secondary phases such as Laves phase [14], carbides [5] and the $\delta$-phase [15]. The oxidation of constituent phases in Ni-based alloys will lead to either compressive or tensile transformation induced residual stresses that will effect the time dependent crack growth rates [16]. In Inconel 718 crack tip oxidation of metal carbides and $\delta$-phase is believed to induce tensile transformation stresses, crack tip anti-shielding and increased susceptibility to time dependent crack growth [16].

The influence of the $\delta$-phase on crack propagation is pointed out in the work by Ponnelle et al. [15]. Where a forged and rolled disc of Inconel 718 was investigated, from which compact tension (CT)- and Kb-specimens were manufactured and subjected to fatigue (triangular waveform, $10 \mathrm{~s}$ up-10 s down) and dwell-fatigue testing (trapezoidal, $10 \mathrm{~s} \mathrm{up}-300 \mathrm{~s}$ dwell $-10 \mathrm{~s}$ down) at $650{ }^{\circ} \mathrm{C}$ and load ratio, $R=0.1$. It was shown that carbides and $\delta$-phase particles are not randomly distributed in this type of forging and that the cellular orientation of $\delta$-phase particles can be linked to the existence of a few hundred microns thick bands, which they referred to as a forming induced arrangement. It was found that the crack preferred to grow in the interface between the $\gamma$-matrix and $\delta$-phase and that the crack growth rates were 
lowest for crack fronts perpendicular to the $\delta$-phase alignments. Contradictory to the study by Ponnelle et al. [15], PÃl'dron et al. [5] found that the precipitation of $\delta$-phase along the grain boundaries did not drastically affect the crack growth rate behaviour.

Ponnelle et al. [15] argued that the delamination mechanism at the $\gamma / \delta$-interface was responsible for the dwell-time crack propagation mechanism. Which was influenced locally by the stress state, which could affect the crack propagation rates under plane stress and plane strain conditions. The influence of stress state is sometimes also visible in the shape of the crack front. In specimens with a semi-circular surface or a corner crack, a phenomenon referred to as "crack tunnelling" is sometimes observed. This is due to the fact that the constraints, which depend on the stress state, are different at the surface and in the specimen interior [17]. Such behaviour, is generally more pronounced under conditions resulting in intergranular cracking [18-21]. Branco et al. [19] observed that during sustained load crack propagation tests the introduction of side grooves, which enhance the plane strain condition of CT-specimens, increase the time dependent crack propagation rate.

Another phenomenon which has been observed but is rarely discussed in the open literature is out-of-plane crack growth [15, 22, 23] which seems to be more pronounced during sustained-load or dwell-fatigue testing of fine grained superalloys. In Moverare et al. [23] it was found that crack deflection occurred during in-phase thermomechanical fatigue testing at $550{ }^{\circ} \mathrm{C}$ when long dwell-times $(6 \mathrm{~h})$ were introduced but not for short ( $5 \mathrm{~min}$ ) or no dwell times. No conclusive explanation to this behaviour is available at the moment and further studies are needed.

The present study is motivated by the fact that no study exists that systematically investigates the effect of anisotropy and stress state on the crack propagation behaviour during dwell-fatigue in a forged Nickel-based alloy. A test program was 
carried out to characterise the dwell-fatigue crack growth resistance in different directions of a Inconel 718 disc forging at $550{ }^{\circ} \mathrm{C}$ using thin and thick (with side groves) CT-samples in order to enable plane stress and plane strain conditions respectively. Detailed metallographic investigations of the tested samples were performed in order to investigate the crack growth mechanisms.

\section{Experimental procedure}

The material used in this study came from an Inconel 718 gas turbine disc, which was press-forged to its basic geometry from a triple melted ingot. Forging was performed below the $\delta$-solvus temperature, obtaining a fine grained microstructure. Consequently, the $\delta$-phase orientates along flow lines during the press-forging. After press-forging the disc was sub-solvus heat-treated accordingly: solution annealing for $3.5 \mathrm{~h}$ at $970{ }^{\circ} \mathrm{C}$, followed by oil quenching and ageing for $8 \mathrm{~h}$ at $720{ }^{\circ} \mathrm{C}$ and $8 \mathrm{~h}$ at $620^{\circ} \mathrm{C}$. The chemical composition is shown in Table 1 . The average grain size was $30 \mu \mathrm{m}$ corresponding to ASTM grain size number 7 according to ASTM E112-96.

Table 1: Composition of elements for Inconel 718 in wt\%.

\begin{tabular}{c|cccccccccccc}
\hline Alloy & $\mathrm{Ni}$ & $\mathrm{Cr}$ & $\mathrm{Fe}$ & $\mathrm{Mo}$ & $\mathrm{Nb}$ & $\mathrm{Co}$ & $\mathrm{C}$ & $\mathrm{Mn}$ & $\mathrm{Si}$ & $\mathrm{Cu}$ & $\mathrm{Al}$ & $\mathrm{Ti}$ \\
\hline Inconel 718 & 54.4 & 17.9 & 16.8 & 3.0 & 5.5 & 0.2 & 0.02 & 0.09 & 0.08 & 0.04 & 0.5 & 1.0 \\
\hline
\end{tabular}

CT specimens were cut from the disc forging in two different orientations and for each orientation in two different thicknesses in order to investigate the influence of plane strain and plane stress condition on the crack propagation rates. The specimen and potential drop (PD) instrumentation is illustrated in Fig. 1 (a). Sample measurements are shown in Fig. 1 (b) and (c) and given in Table 2. The orientations C-S and S-C indicate how the samples were cut from the disc forging and are illustrated in Fig. 1 (d). Pre-cracking were performed at ambient temperature using the 
Table 2: Summary of elevated temperature crack growth tests, with the constants $a_{n}=12.5 \mathrm{~mm}$, $W=25 \mathrm{~mm}$, Temperature $550{ }^{\circ} \mathrm{C}$, and load ratio $R=0.05$.

\begin{tabular}{cccccccc}
\hline Sample \# & Direction & $B$ & $b_{n}[\mathrm{~mm}]$ & Dwell-time $[\mathrm{s}]$ & $\Delta P[\mathrm{~N}]$ & $a_{\text {valid }}[\mathrm{mm}]$ & $a_{\text {final }}[\mathrm{mm}]$ \\
\hline 1 & & {$[\mathrm{~mm}]$} & & & & & \\
2 & S-C & 12.50 & 9.50 & 2160 & 2500 & 19 & 19 \\
3 & S-C & 2.25 & 2.25 & 2160 & 560 & 19 & 19 \\
4 & S-C & 2.49 & 2.49 & 90 & 618 & 19 & 19 \\
5 & S-C & 12.50 & 9.50 & 90 & 2500 & 19 & 19 \\
6 & C-S & 12.50 & 9.50 & 2160 & 2500 & 18 & 20 \\
7 & C-S & 2.77 & 2.77 & 2160 & 700 & 15.3 & 20 \\
8 & C-S & 12.50 & 9.50 & 90 & 2500 & 18.8 & 20 \\
\hline
\end{tabular}

compliance method for crack length measurements and PD was used during testing at $550{ }^{\circ} \mathrm{C}$. Both pre-cracking and the subsequent elevated temperature testing were performed according to ASTM E647-08. Electro-discharge machined starter notches were used measuring $a_{n}=12.5 \mathrm{~mm}$, Fig. 1 (c), and the samples were fatigue precracked at room temperature to a crack length of $a_{0}=16 \mathrm{~mm}$ using a frequency of $10 \mathrm{~Hz}$. The load conditions $\Delta P$ and $R$ during the pre-cracking was the same as for the subsequent high temperature testing and are given in Table 2. One specimen was used for each test condition.

High temperature crack propagation tests were conducted at $550{ }^{\circ} \mathrm{C}$ using $90 \mathrm{~s}$ and $2160 \mathrm{~s}$ dwell-times, with a constant ramp up/ramp down rate yielding a $10 \mathrm{~s}$ single ramp time each for loading and unloading. Testing was done using a $100 \mathrm{kN}$ Zwick servo electric Kappa 50DS tensile testing machine, equipped with a three zone (high temperature) furnace and a $20 \mathrm{~A}$ pulsed direct current potential drop (DCPD) system. Table 2 summarises all the parameters used. 
Data was evaluated using evaluation code for compact tension samples [24] and more details regarding the test setup are covered in reference [25]. A crack is not allowed to deviate by more that $10^{\circ}$ from its point of initiation at the machined notch for a test to be considered valid the according to ASTM E647-08. If the crack deviates by more than $10^{\circ}$, the valid crack length is underestimated and the analytical solution of the stress intensity factor, $K[\mathrm{MPa} \sqrt{m}]$, for CT-specimens obtained from ASTM E647-08 will be inaccurate. In Table 2, $a_{\text {valid }}$ and $a_{\text {final }}$ are the valid and final crack lengths respectively

All samples presented in Table 2 were run to fracture in order to study fracture surfaces. After which some specimens were sectioned as-is, parallel to the centreline and perpendicular to the surface of the crack, so that the crack path could be studied in a cross-section. These samples were prepared by grinding and careful mechanical polishing but no etching. Two additional 90 s plane stress specimens were interrupted before final fracture in order to enable studies of the crack tip in cross-section. Data from these tests are presented in the supplementary material.

A Hitachi SU70 FEG analytical scanning electron microscope (SEM), operating at $1.5-20 \mathrm{kV}$ was used together with various techniques such as electron channelling contrast imaging (ECCI) [26] to get high quality, high contrast images of the crack growth appearance and the microstructure, electron back scatter diffraction (EBSD) to analyse grain orientation with orientation imaging maps (OIM) with a step size of $0.5 \mu \mathrm{m}, 20 \mathrm{~mm}$ working distance, and $20 \mathrm{kV}$ acceleration voltage. Optical microscopy was used to study fracture surfaces as well as crack paths.

\section{Results}

Crack growth rate $\mathrm{d} a / \mathrm{d} N$ versus $\Delta K=K_{\max }-K_{\min }$, where $K_{\min }$ and $K_{\max }$ are minimum and maximum stress intensity factors $[\mathrm{MPa} \sqrt{m}]$ respectively are presented 
in Fig. 2. A test is considered invalid if the main crack grows out of plane by more than $10^{\circ}$ according to both ASTM E399-97 and ASTM 647-08. The dashed circles and filled dots in Fig. 2 mark where the cracks start to grow out of plane by more than $10^{\circ}$ perpendicular to the loading direction, i.e., the evaluation method according to ASTM E399-97 and ASTM 647-08 used is regarded invalid because of a change in stress mode resulting in an underestimation of the crack length $a$. The black circles mark the theoretical validity of the tests. Only samples cut in the $\mathrm{C}-\mathrm{S}$ direction show out of plane crack growth.

An increase in dwell-time drastically affects the crack growth rate. A longer dwell-time results in an accelerated crack growth rate, approximately a factor ten, for all samples cut in both the $\mathrm{S}-\mathrm{C}$ and $\mathrm{C}-\mathrm{S}$ directions. Crack growth rates are significantly faster in the $\mathrm{S}-\mathrm{C}$ direction compared to the $\mathrm{C}-\mathrm{S}$ directions and there is a tendency for higher crack propagation rates for the plane strain condition compared to the plane stress condition, especially when longer dwell-times are applied.

Microstructure images of plane stress S-C (sample 3, left column) and C-S (sample 6, right column) dwell-time samples are shown in Fig 3 (a) and (b) respectively. The arrows mark $\delta$-phase orientation and the ellipsis mark $\delta$-phase clusters (forming induced arrangement). EBSD analysis adds further information regarding grain orientation, Fig (c) and (d). $\Sigma 3-\Sigma 29$ CSL grain boundary orientations are shown in (e) and (f), as well as pole density figures (g) and (h). The CSL grain boundary orientation maps and pole density figures $(\mathrm{e})-(\mathrm{h})$ show that the $\mathrm{S}-\mathrm{C}$ and $\mathrm{C}-\mathrm{S}$ samples are very similar and that there is no evident crystallographic texture. The CSL grain boundary orientation maps show that except for a large amount of twin boundaries $(\Sigma 3)$ the CSL grain boundaries are randomly distributed.

Fracture surfaces and cross sections of both an S-C (sample 1) and C-S (sample 5) plane strain test sample run with $2160 \mathrm{~s}$ dwell-times are shown in Fig. 4. A cross 
section of sample 1 shows that the crack grew perpendicular to the loading direction in (a). The fracture surface of sample 1 in (b) is much flatter "in plane" compared to the fracture surface in (d) from sample 5 which has grown significantly "out of plane", even though the sample had side grooves. The thin (plane stress) S-C and C-S samples show the same characteristic appearance.

In Fig. 5, microstructure and cracking behaviour is shown for samples cut in both S-C (left column) and C-S (right column) directions respectively. The crack tip was observed to frequently grow in the interface between the $\gamma$-matrix and $\delta$ phase, indicated by ellipsis in (b) and (f) and an arrow in (d). Cracking behaviour was mainly intergranular for both dwell-times, $90 \mathrm{~s}$ and $2160 \mathrm{~s}$, as seen in the crosssections in (b), (c), and (f). Secondary cracks growing in the interface between the $\gamma$-matrix and $\delta$-phase are shown in (a), (b), and (f). $\delta$-phase delamination was also observed in grain boundaries, Fig. 5 (b) and (e). The crack tip also show signs of blunting which is expected as an effect of the superimposed dwell-time. The blunting effect is illustrated in (a) and (d). Despite the intergranular cracking behaviour, slip bands and plastically deformed material surrounding the crack path is shown in (b), (c), and (f) as well as secondary cracks oriented in the same directions as the $\delta$-phases, indicating that the fracture of the grain boundaries during crack propagation is not fully brittle. The same characteristic appearance was observed for the thick (plane strain) samples regardless of superimposed dwell-time.

\section{Discussion}

Turbine discs manufactured from wrought fine grained polycrystalline nickel base superalloys, such as Inconel 718, is in many situations limited by its susceptibility to fast intergranular cracking during extended dwell-times at high temperatures and

high tensile stresses [23]. It is well established that time dependent intergranular 
cracking of nickel-base superalloys, under both sustained and cyclic loads, is dominated by environmental interactions with oxygen and or other embrittling species at the crack tip resulting in dynamic embrittlement (DE) or stress accelerated grain boundary oxidation (SAGBO) [27, 28]. Previous studies [29, 30] have shown that complex oxides of $\mathrm{Ni}, \mathrm{Cr}$, and $\mathrm{Fe}$, as well as oxides formed from niobium carbides along grain boundaries, can be formed at the crack tip in Inconel 718. The transition from from transgranular to intergranular crack growth behaviour is thus typically associated with an acceleration in crack growth rate, especially in combination with dwell-times. This conforms with our observations that the crack growth rate at $550{ }^{\circ} \mathrm{C}$ increased when a dwell time of $2160 \mathrm{~s}$ was applied at the maximum load, see Fig. 2 .

Retardation of the crack growth rate, on the other hand, is typically associated with a significant degree of plastic deformation, crack tip blunting and branching. Also creep deformation will lead to stress relaxation ahead of the crack tip that will reduce the crack propagation rate [6-8]. The plastic deformation seen in Fig. 5 (c) also led to crack tip blunting and branching in connection to slip bands in (b) and (d). So it is clear that mechanisms leading to both acceleration and retardation of the crack growth rate are present at the same time and the overall response depends on all active mechanisms. However, the most interesting result in the present study is the observation of a strong anisotropy in crack propagation rate between different specimen orientations, see Fig. 2.

The microstructure has been analysed in order to investigate what microstructural features effect the anisotropy in crack growth behaviour. The OIM:s and pole density figure show no signs of preferred grain orientations, nor any significant elongation of the grains in certain directions of the forging. This was done to verify that the sample cross sections are the same, just oriented with a $90^{\circ}$ difference. No changes in 
crack growth behaviour due to grain orientation can be evinced. Certain special CSL grain boundaries, have been proposed to be less prone to intergranular cracking, and could be the reason for the difference in crack growth behaviour. Thermomechanicalprocessing is used to achieve a higher fraction of CSL grain boundaries, to reduce the sensitivity for dwell-time cracking [12,31]. Apart from twin boundaries, $(\Sigma 3)$, a low fraction of CSL grain boundaries are present in the material, listed in Table 3. No preferred orientational aspects can be seen for the CSL grain boundaries investigated displayed in Fig.3 (e) and (f). Due to the small differences in CSL fractions listed in Table 3, no distinct conclusions can be drawn regarding anisotropy effects. The $\delta$-phase is the only observed microstructural feature which exhibits a preferred orientation. It is elongated perpendicular to the force applied during the die forging operation, illustrated in Fig. 3 (a) and (b). The orientational effect (forming induced arrangement) of the $\delta$-phase has been reported to significantly affect crack propagation behaviour in Inconel 718 [15]. Crack growth rates were higher in the S-C samples with the $\delta$-phase discs oriented longitudinally perpendicular to the loading direction. The Nb-rich $\delta$-phase discs are prone to oxidation [13, 29], leading to a weakening of the $\gamma-\delta$ interface. Delamination of the interface occurs when a tensile load is applied resulting in faster crack growth. Delamination of the $\gamma-\delta$ interface is shown in Fig. 5 (b) and (e). Similar observations have also been reported in [15]. Samples cut in the $\mathrm{C}-\mathrm{S}$ direction show the slowest crack growth rates because the $\gamma-\delta$ interface is shorter perpendicular to the loading direction compared to the $\mathrm{S}-\mathrm{C}$ samples. The cracks in the $\mathrm{C}-\mathrm{S}$ samples deviates from planar crack growth when reaching $\delta$-phase due to the weakening of the $\gamma-\delta$ interface. Resulting in crack growth more parallel to the loading direction along the interface as seen in $5(\mathrm{~d})$. When the crack deflects, the driving force is retarded, lowering the crack propagation rates even if the crack propagates along the $\gamma-\delta$ interface. 
Table 3: Fraction of coincidence site lattice grain boundaries, $\Sigma 3-\Sigma 29$ (length fraction [\%]).

\begin{tabular}{|c|c|c|c|c|c|c|c|c|c|c|c|c|c|c|}
\hline \multirow[t]{2}{*}{$\Sigma$ value } & S- & $\mathrm{C}-\mathrm{S}$ & $\Sigma$ & S- & C-S & $\Sigma$ & S- & C-S & $\Sigma$ & S- & $\mathrm{C}-\mathrm{S}$ & \multirow[t]{2}{*}{$\Sigma$} & S- & $\mathrm{C}-$ \\
\hline & C & & & C & & & C & & \multicolumn{3}{|c|}{ C } & & \multicolumn{2}{|l|}{$\mathrm{C}$} \\
\hline 3 & 48.52 & 42.87 & $13 a$ & 0.00 & 0.00 & $19 \mathrm{a}$ & 0.06 & 0.03 & $25 \mathrm{a}$ & 0.00 & 0.00 & \multirow[t]{5}{*}{$29 \mathrm{~b}$} & \multirow[t]{5}{*}{0.14} & \multirow[t]{5}{*}{0.14} \\
\hline 5 & 0.16 & 0.18 & $13 \mathrm{~b}$ & 0.00 & 0.04 & $19 \mathrm{~b}$ & 0.00 & 0.10 & $25 \mathrm{~b}$ & 0.63 & 0.14 & & & \\
\hline 7 & 0.22 & 0.48 & 15 & 0.08 & 0.30 & $21 \mathrm{a}$ & 0.00 & 0.13 & $27 \mathrm{a}$ & 0.02 & 0.48 & & & \\
\hline 9 & 1.02 & 0.90 & $17 \mathrm{a}$ & 0.00 & 0.17 & $21 \mathrm{~b}$ & 0.00 & 0.11 & $27 \mathrm{~b}$ & 0.00 & 0.01 & & & \\
\hline \multirow[t]{2}{*}{11} & 0.20 & 0.74 & $17 \mathrm{~b}$ & 0.33 & 0.42 & 23 & 0.25 & 0.14 & $29 a$ & 0.16 & 0.79 & & & \\
\hline & & & & & & & & & & & & Sum & 51.77 & 48.17 \\
\hline
\end{tabular}

Our crack growth rates reported until their points of validity, and correspond well to that reported by Ponelle et al. [15] (disc) for both directions, Gustafsson et al. [9, 32] (bar material), for the $\mathrm{C}-\mathrm{S}$ direction, all conducted at similar temperatures, $550-650{ }^{\circ} \mathrm{C}$.

No significant difference in the tendency for blunting or crack branching has been observed between the two different orientations. Blunting of the crack tip will impede the crack growth rate since the energy needed to propagate a blunted crack tip is higher compared to a sharp crack tip. Studying the crack tip at higher magnification revealed a tendency for what could be environmental assisted cracking in the form of nano sized pores seen in Fig. 5 (d) which has also been observed in [10]. From the blunted crack tip in Fig. 5 (d), what could be a small crack (marked by a arrow) in front of the crack tip has been formed growing towards the $\delta$-phase. Which would propagate towards the interface causing delamination of the $\delta-\gamma$ interface. Blunting and environmental effects such as DE and SAGBO can probably not be solely used to determine the anisotropy effects in our material. It is more likely to be microstructure dependent i.e., $\delta$-phase orientation. The main difference between the two sample orientations, is the tendency for crack deflection. In contradiction to the S-C samples with a crack growth perpendicular to the loading direction, Fig. 4 (a), 
crack growth in samples cut in the $\mathrm{C}-\mathrm{S}$ direction was out of plane, almost parallel to the loading direction, Fig. 4 (c).

For arbitrary crack shapes, the geometrical plane stress/strain conditions may effect the crack propagation behaviour which makes fatigue life predictions more challenging. For test specimens with a well defined geometry, the effect is manifested through differences in crack propagation rates between thin and thick samples with through-thickness cracks or tunnelling effects in samples with surface cracks [33-36]. Crack tunnelling during cyclic loading could be related to the amount of crack closure present. Higher closure values will be associated with more plane stress conditions, giving a lower propagation rate [37, 38]. During sustained loading, crack tunnelling is more difficult to relate to crack closure, but should still depend on the constraint level. Long dwell-times are known to cause crack tunnelling [17, 20, 22, 39] with a strong growth toward the depth for certain specimen geometries and load cycles. In the present study two types of specimens have been used to promote either plane strain conditions (thick samples with side groves) or plane stress conditions (thin samples). From Fig. 2 it is clear that the plane stress/strain condition have a minor effect on the crack propagation rate compared to the dwell time effect or the anisotropy effect present in the material. It is only for the condition with the highest crack propagation rates, the S-C orientation and 2160s dwell time were a significant thickness effect is observed.

\section{Conclusions}

Dwell-fatigue crack growth tests was performed on CT specimens. The specimens were cut in two different orientations and each orientation in two thicknesses from an Inconel 718 disc forging. Tests were run at $550{ }^{\circ} \mathrm{C}$ with two different dwell-times, 
$90 \mathrm{~s}$ and $2160 \mathrm{~s}$, in order to investigate the effects of anisotropy on dwell-fatigue and crack growth behaviour. The following conclusions can be drawn from this work:

- Crack growth is approximately a factor ten faster in the samples cut in the $\mathrm{S}-\mathrm{C}$ compared to the $\mathrm{C}-\mathrm{S}$ direction due to the $\delta$-phases being elongated along the crack growth direction.

- The 2160 s dwell-time tests show a crack growth rate approximately a factor ten faster than the $90 \mathrm{~s}$ dwell-time tests, for both directions respectively.

- Fatigue crack growth rates are slightly faster for plane strain than for plane stress conditions for the highest crack propagation rates.

- Crack growth occurs preferably in the interface between the $\gamma$-matrix and $\delta$ phase.

- The small orientational and fractional difference in coincident site lattice grain boundaries and/or crystallographic texture could not explain the anisotropy effects.

As a final remark, if possible, the manufacturing process and heat treatments should be conducted in such a way that the $\delta$-phases were to be optimally oriented to reduce the risk of catastrophic failure of turbine discs.

\section{Acknowledgements}

The authors would like to thank Agora Materiae, graduate school, the Swedish Government Strategic Research Area in Materials Science on Functional Materials at Linköping University (Faculty Grant SFOâ̆ ŚSMatâẮSLiU 2009âĂŚS00971) for financial support, and the project teams at Linköping University, Siemens Industrial 
Turbomachinery AB and GKN Aerospace Engine Systems for valuable discussions. This research has been funded by the Swedish Energy Agency, Siemens Industrial Turbomachinery AB, GKN Aerospace Engine Systems, and the Royal Institute of Technology through the Swedish research program TURBO POWER, the support of which is gratefully acknowledged. Also, a special thank you to Ph.D. Christopher Tholander and Mattias Lundberg for all the valuable help.

\section{References}

[1] D. Leo Prakash, M. Walsh, D. Maclachlan, A. Korsunsky, Crack growth micromechanisms in the IN718 alloy under the combined influence of fatigue, creep and oxidation, International Journal of Fatigue 31 (11-12) (2009) 1966-1977. doi:10.1016/j.ijfatigue.2009.01.023.

[2] E. Andrieu, R. Molins, H. Ghonem, A. Pineau, Intergranular crack tip oxidation mechanism in a nickel-based superalloy, Materials Science and Engineering A 154 (1) (1992) 21-28. doi:10.1016/0921-5093(92)90358-8.

[3] R. Molins, G. Hochstetter, J. C. Chassaigne, E. Andrieu, Oxidation effects on the fatigue crack growth behaviour of alloy 718 at high temperature, Acta Materialia 45 (2) (1997) 663-674.

[4] J. A. Pfaendtner, C. J. Mcmahon JR., Oxygen-induced intergranular cracking of a Ni-base alloy at elevated temperatures - an example of dynamic embrittlement, Acta Materialia 49 (16) (2001) 3369-3377.

[5] J. P. Pédron, A. Pineau, The Effect of Microstructure and Environment on the Crack Growth Behaviour of Inconel 718 Alloy at 650 Âr̆C under Fatigue , 
Creep and Combined Loading, Materials Science and Engineering 56 (2) (1982) $143-156$.

[6] H. Li, J. Sun, M. Hardy, H. Evans, S. Williams, T. Doel, P. Bowen, Effects of microstructure on high temperature dwell fatigue crack growth in a coarse grain PM nickel based superalloy, Acta Materialia 90 (2015) 355-369. doi:10.1016/j.actamat.2015.02.023.

[7] J. Byrne, R. Hall, L. Grabowski, Elevated temperature fatigue crack growth under dwell conditions in Waspaloy, International Journal of Fatigue 19 (5) (1997) 359-367.

[8] X. Liu, B. Kang, K.-m. Chang, The effect of hold-time on fatigue crack growth beha $\mathrm{v}$ iors of WASPALOY alloy at ele v ated temperature, Materials Science and Engineering A 340 (1) (2003) 8-14.

[9] D. Gustafsson, E. Lundström, High temperature fatigue crack growth behaviour of Inconel 718 under hold time and overload conditions, International Journal of Fatigue 48 (2013) 178-186.

[10] J. Saarimäki, J. Moverare, R. Eriksson, S. Johansson, Influence of overloads on dwell time fatigue crack growth in Inconel 718, Materials Science and Engineering: A 612 (2014) 398-405. doi:10.1016/j.msea.2014.06.068.

[11] A. K. Koul, P. Au, N. Bellinger, R. Thamburaj, W. Wallace, J-P. Immarigeon, Development of a Damage Tolerant Microstructure for Inconel 718 Turbine Disc Material, Superalloys, Sixth International Symposium (1988).

[12] U. Krupp, Improving the resistance to intergranular cracking and corrosion at 
elevated temperatures by grain-boundary-engineering-type processing, Journal of Materials Science 43 (11) (2008) 3908-3916. doi:10.1007/s10853-007-2363-6.

[13] M. Gao, D. J. Dwyer, R. P. Wei, Nionium enrichment and environmental enhancement of creep crack gowth in nickel-base superalloys, Scripta Metallurgica et Materialia 32 (8) (1995) 1169-1174. doi:10.1016/0956-716X(95)00120-K.

[14] J. J. Schirra, R. H. Caless, R. W. Hatala, The effect of laves phase on the mechanical properties of wrought and cast + HIP inconel 718, in: Superalloys 718, 625 and Various Derivatives, 1991, pp. 375-388.

[15] S. Ponnelle, B. Brèthes, A. Pineau, Orientational effects and influence of delta phase on fatigue crack growth rates in a forged disc of Inco718 superalloy, Superalloys 718, 625, 706 and Derivatives 92 (January 2001) (2001) 307-319. doi:10.7449/2001/Superalloys.

[16] K. S. Chan, M. P. Enright, J. Moody, S. H. K. Fitch, A microstructure-based time-dependent crack growth model for life and reliability prediction of turbopropulsion systems, Metallurgical and Materials Transactions A: Physical Metallurgy and Materials Science 45 (1) (2014) 287-301. doi:10.1007/s11661-0131971-9.

[17] F. V. Antunes, J. M. Ferreira, C. M. Branco, J. Byrne, Influence of stress state on high temperature fatigue crack growth in Inconel 718, Fatigue and Fracture of Engineering Materials and Structures 24 (2) (2001) 127-135.

[18] M. R. Bache, W. J. Evans, M. C. Hardy, The effects of environment and loading waveform on fatigue crack growth in Inconel 718, International Journal of Fa- 
tigue 21, Supple (July 2016) (1999) S69-S77. doi:10.1016/S0142-1123(99)000572 .

[19] C. M. Branco, J. Baptista, J. Byrne, Crack growth under constant sustained load at elevated temperature in IN718 superalloy, Materials at High Temperatures 16 (1) (1999) 27-35. doi:10.3184/096034099783641227.

[20] P. Heuler, E. Affeldt, R. J. H. Wanhill, Effects of Loading Waveform and Stress Field on High Temperature Fatigue Crack Growth of Alloy 718, Materialwissenschaft und Werkstofftechnik 34 (9) (2003) 790-796. doi:10.1002/mawe.200300663.

[21] E. Storgärds, K. Simonsson, S. Sjöström, Three-dimensional crack growth modelling of a Ni-based superalloy at elevated temperature and sustained loading, Theoretical and Applied Fracture Mechanics 81 (2016) (2016) 2-10. doi:10.1016/j.tafmec.2015.11.008.

[22] J. Tong, T-stress and its implications for crack growth, Engineering Fracture Mechanics 69 (12) (2002) 1325-1337. doi:10.1016/S0013-7944(02)00002-4.

[23] J. Moverare, D. Gustafsson, Hold-time effect on the thermo-mechanical fatigue crack growth behaviour of Inconel 718, Materials Science and Engineering A 528 (29-30) (2011) 8660-8670.

[24] J. Saarimäki, Dwell-fatigueEvaluationForCompactTensionSamples (2016). doi:10.5281/zenodo.61241.

[25] J. Saarimäki, J. J. Moverare, M. H. Colliander, Time- and cycle-dependent crack propagation in Haynes 282, Materials Science and Engineering: A 658 (2016) 463-471. doi:10.1016/j.msea.2016.01.111. 
[26] R. J. Kamaladasa, Y. N. Picard, Basic Principles and Application of Electron Channeling in a Scanning Electron Microscope for Dislocation Analysis, Microscopy: Science, Technology, Applications and Eduaction (2010) 1583-1590.

[27] K. Wackermann, U. Krupp, H. J. Christ, Effects of the environment on the crack propagation behavior of IN718 in the temperature range of the dynamic embrittlement, in: ASTM Special Technical Publication, Vol. 1539 STP of ASTM International Symposium on Creep-Fatigue Interactions: Test Methods and Models, Siegen, Germany, 2011, pp. 297-312.

[28] D. A. Woodford, Gas phase embrittlement and time dependent cracking of nickel based superalloys, Energy Materials: Materials Science and Engineering for Energy Systems 1 (1) (2006) 59-79. doi:10.1179/174892306X99679.

[29] L. Viskari, M. Hörnqvist, K. L. Moore, Y. Cao, K. Stiller, Intergranular crack tip oxidation in a Ni-base superalloy, Acta Materialia 61 (10) (2013) 3630-3639. doi:http://dx.doi.org/10.1016/j.actamat.2013.02.050.

[30] M. Gao, D. J. Dwyer, R. P. Wei, CHEMICAL AND MICROSTRUCTURAL GROWTH IN INCONEL ASPECTS 718 ALLOY OF CREEP CRACK, in: Superalloys 718, 625, 706 and Various Derivatives, 1994, pp. 581-592.

[31] U. Krupp, Fatigue Crack Propagation in Metals and Alloys: Microstructural Aspects and Modelling Concepts, Wiley, 2007.

[32] D. Gustafsson, E. Lundström, K. Simonsson, Modelling of high temperature fatigue crack growth in Inconel 718 under hold time conditions, International Journal of Fatigue 52 (2013) 124-130. doi:10.1016/j.ijfatigue.2013.03.004. 
[33] J. C. Newman, C. A. Bigelow, K. N. Shivakumar, Three-dimensional elasticplastic finite-element analyses of constraint variations in cracked bodies, Engineering Fracture Mechanics 46 (1) (1993) 1-13. doi:10.1016/00137944(93)90299-8.

[34] M. L. Zhu, F. Z. Xuan, S. T. Tu, Observation and modeling of physically short fatigue crack closure in terms of in-situ SEM fatigue test, Materials Science and Engineering A 618 (2014) 86-95. doi:10.1016/j.msea.2014.08.021.

[35] J. P. Tan, G. Z. Tu, S. T.Wang, F. Z. Xuan, Characterization and correlation of $3-\mathrm{D}$ creep constraint between axially cracked pipelines and test specimens, Engineering Fracture Mechanics journal 136 (2015) 96-114. doi:10.1016/j.ijpvp.2012.06.004.

[36] M. L. Zhu, F. Z. Xuan, S. T. Tu, Effect of load ratio on fatigue crack growth in the near-threshold regime: A literature review, and a combined crack closure and driving force approach, Engineering Fracture Mechanics 141 (2015) 57-77. doi:10.1016/j.engfracmech.2015.05.005.

[37] J. C. Newman, A crack opening stress equation for fatigue crack growth, International Journal of Fracture 24 (4) (1984) 131-135. doi:10.1007/BF00020751.

[38] M. A. James, J. C. Newman, The effect of crack tunneling on crack growth: Experiments and CTOA analyses, Engineering Fracture Mechanics 70 (3-4) (2003) 457-468. doi:10.1016/S0013-7944(02)00131-5.

[39] E. Storgärds, J. Saarimäki, K. Simonsson, S. Sjöström, D. Gustafsson, T. Månsson, J. Moverare, J. Saarimäki, T. Månsson, K. Simonsson, S. Sjöström, 
J. Moverare, Scatter in Dwell Time Cracking for a Ni-Based Superalloy in Combination With Overloads, Journal of Engineering for Gas Turbines and Power 138 (1) (2015) 1-7. doi:10.1115/1.4031157. 


\section{List of Figures}

1 (a) A 3D view of an instrumented CT specimen with side grooves. (b) $\&$ (c) Schematic rear- and side-view drawings, with all measurements given in $\mathrm{mm}$. (d) An illustration of the sample cutting orientation. . . 23

2 All samples compiled showing the effect of anisotropy between samples cut in the $\mathrm{S}-\mathrm{C}$ and $\mathrm{C}-\mathrm{S}$ direction. The dashed circles and filled dots show where the cracks start to grow out of plane more than $10^{\circ}$ perpendicular to the loading direction, circles show the theoretical validity of the $\Delta K$ calculation according to ASTM E399-97. . . . . .

3 Microstructure of samples cut in the $\mathrm{S}-\mathrm{C}$ (left column) and $\mathrm{C}-\mathrm{S}$ (right column) directions. (a) and (b) General microstructure, $\delta$-phase orientation marked with arrows and the circles mark $\delta$-phase clusters. (c) and (d) OIM:s of the microstructure in the $\mathrm{S}-\mathrm{C}$ and $\mathrm{C}-\mathrm{S}$ direction respectively. (e) and (f) CSL grain boundary orientation, $\Sigma 3-\Sigma 29$, maps for the $\mathrm{S}-\mathrm{C}$ and $\mathrm{C}-\mathrm{S}$ direction respectively. (g) and (h) pole density figures of the $\mathrm{S}-\mathrm{C}$ and $\mathrm{C}-\mathrm{S}$ directions respectively. . . . . .

4 Cross section images of both an $\mathrm{S}-\mathrm{C}$ and $\mathrm{C}-\mathrm{S}$ test sample (a) Cross section of sample 1 cut in the $\mathrm{S}-\mathrm{C}$ direction show crack growth to be perpendicular to the loading direction. (b) $1 / 2$ fracture surface of sample 1 cut in the $\mathrm{S}-\mathrm{C}$ direction. (c) Cross section of sample 5 cut in the $\mathrm{C}-\mathrm{S}$ direction shows crack growth to be more parallel to the loading direction. (d) Fracture surface of sample 5 cut in the $\mathrm{C}-\mathrm{S}$ direction, the square marks the inclined area of the fracture surface in

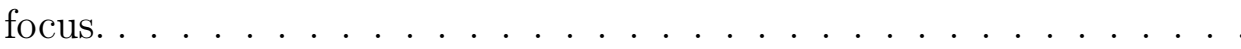

5 Cross section images of sample 3 (S-C, left column) and sample 6 (C-S, right column), a plane stress, with $90 \mathrm{~s}$ and $2160 \mathrm{~s}$ dwell-times respectively. (a) The secondary crack tip grows in the interface between the $\delta$-phase and $\gamma$-matrix. (b) Intergranular crack growth shows delamination of $\delta$-phase as well as secondary cracks grows into the interface between the $\delta$-phase and $\gamma$-matrix. (c) Plastically deformed material and slip bands. (d) The blunting effect of a secondary crack tip. (e) $\delta$-phase delamination. (f) Intergranular crack growth as well as secondary cracks growing into the interface between the $\delta$-phase and $\gamma$-matrix. . . . . . . . . . . . . . . . . . . . . . . 2 
(a)

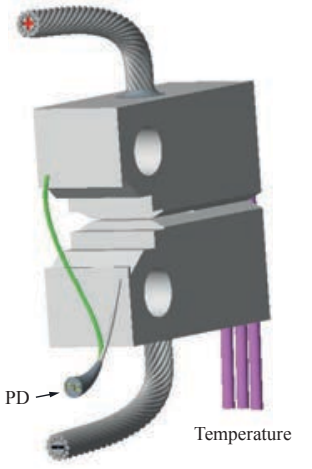

(b)

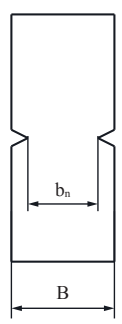

(c)

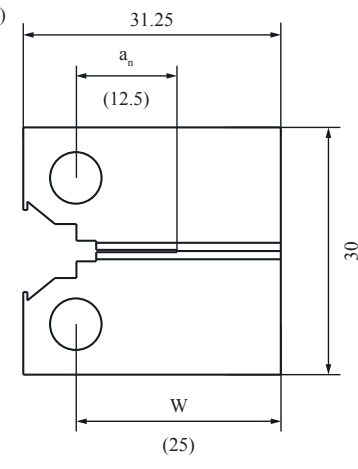

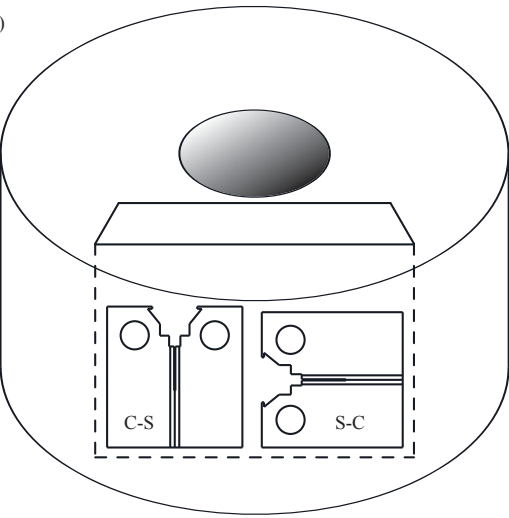

Figure 1: (a) A 3D view of an instrumented CT specimen with side grooves. (b) \& (c) Schematic rear- and side-view drawings, with all measurements given in mm. (d) An illustration of the sample cutting orientation. 


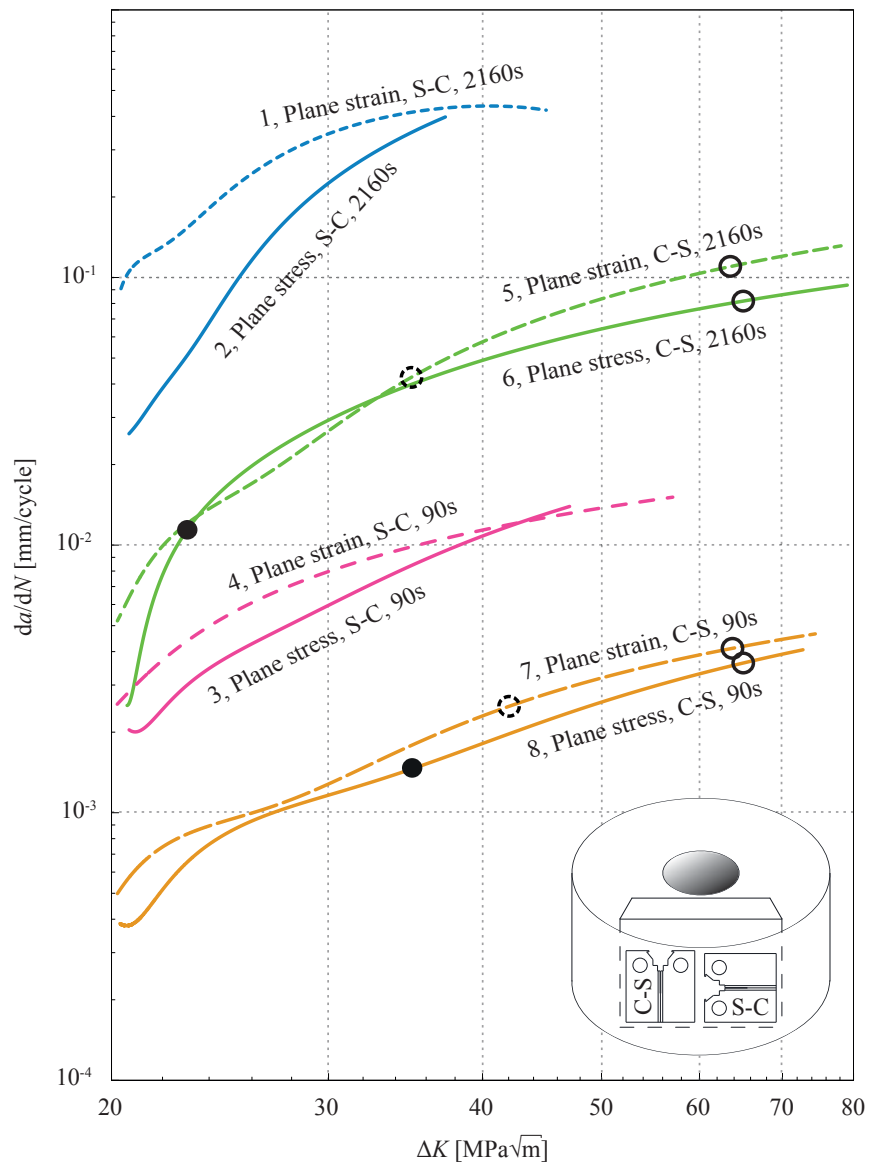

Figure 2: All samples compiled showing the effect of anisotropy between samples cut in the $\mathrm{S}-\mathrm{C}$ and $\mathrm{C}-\mathrm{S}$ direction. The dashed circles and filled dots show where the cracks start to grow out of plane more than $10^{\circ}$ perpendicular to the loading direction, circles show the theoretical validity of the $\Delta K$ calculation according to ASTM E399-97. 

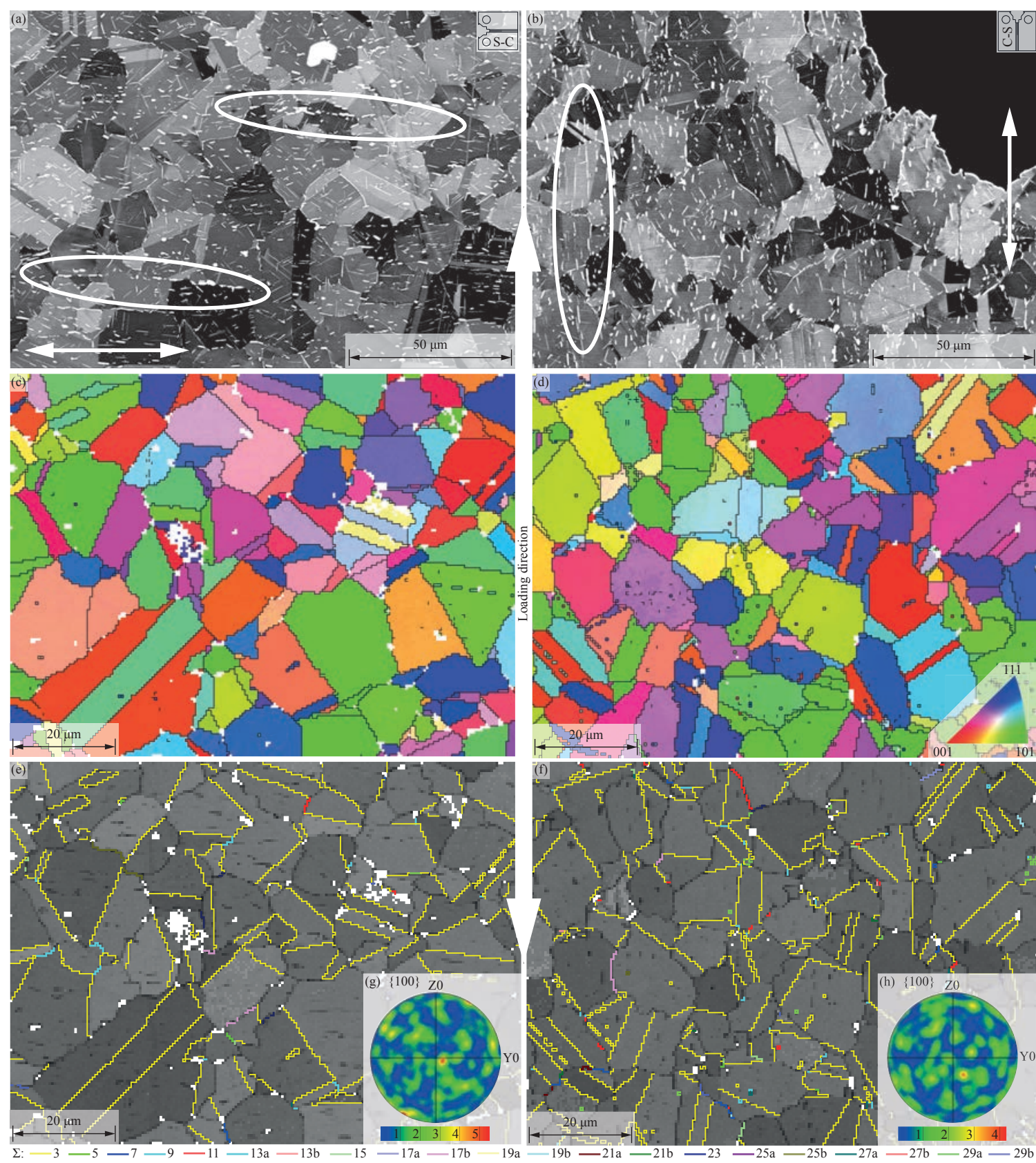

Figure 3: Microstructure of samples cut in the S-C (left column) and C-S (right column) directions. (a) and (b) General microstructure, $\delta$-phase orientation marked with arrows and the circles mark $\delta$-phase clusters. (c) and (d) OIM:s of the microstructure in the $\mathrm{S}-\mathrm{C}$ and $\mathrm{C}-\mathrm{S}$ direction respectively. (e) and (f) CSL grain boundary orientation, $\Sigma 3-\Sigma 29$, maps for the S-C and C-S direction respectively. (g) and (h) pole density figures of the $\mathrm{S}-\mathrm{C}$ and $\mathrm{C}-\mathrm{S}$ directions respectively. 


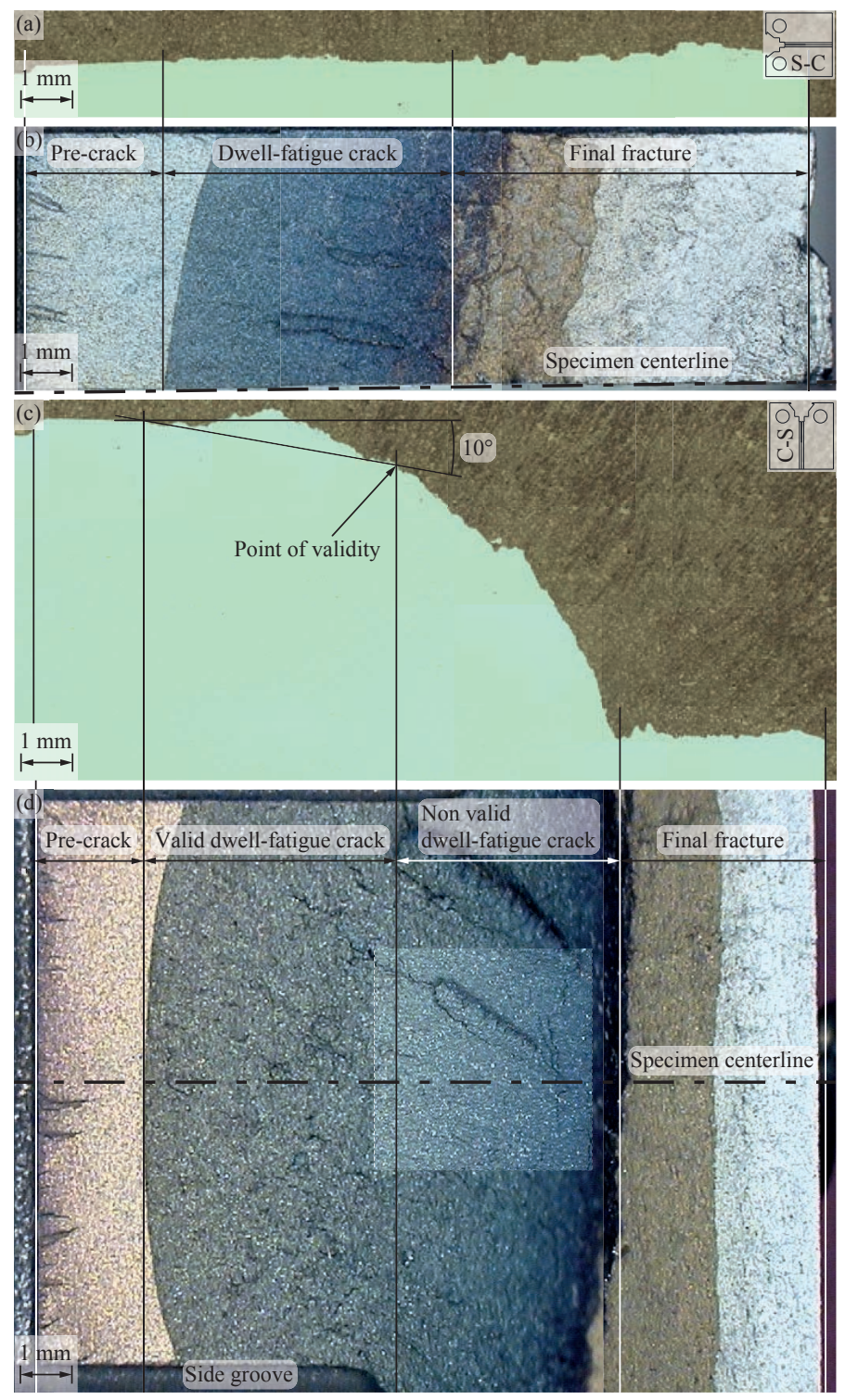

Figure 4: Cross section images of both an S-C and C-S test sample (a) Cross section of sample 1 cut in the $\mathrm{S}-\mathrm{C}$ direction show crack growth to be perpendicular to the loading direction. (b) $1 / 2$ fracture surface of sample 1 cut in the $\mathrm{S}-\mathrm{C}$ direction. (c) Cross section of sample 5 cut in the $\mathrm{C}-\mathrm{S}$ direction shows crack growth to be more parallel to the loading direction. (d) Fracture surface of sample 5 cut in the $\mathrm{C}-\mathrm{S}$ direction, the square marks the inclined area of the fracture surface in focus. 

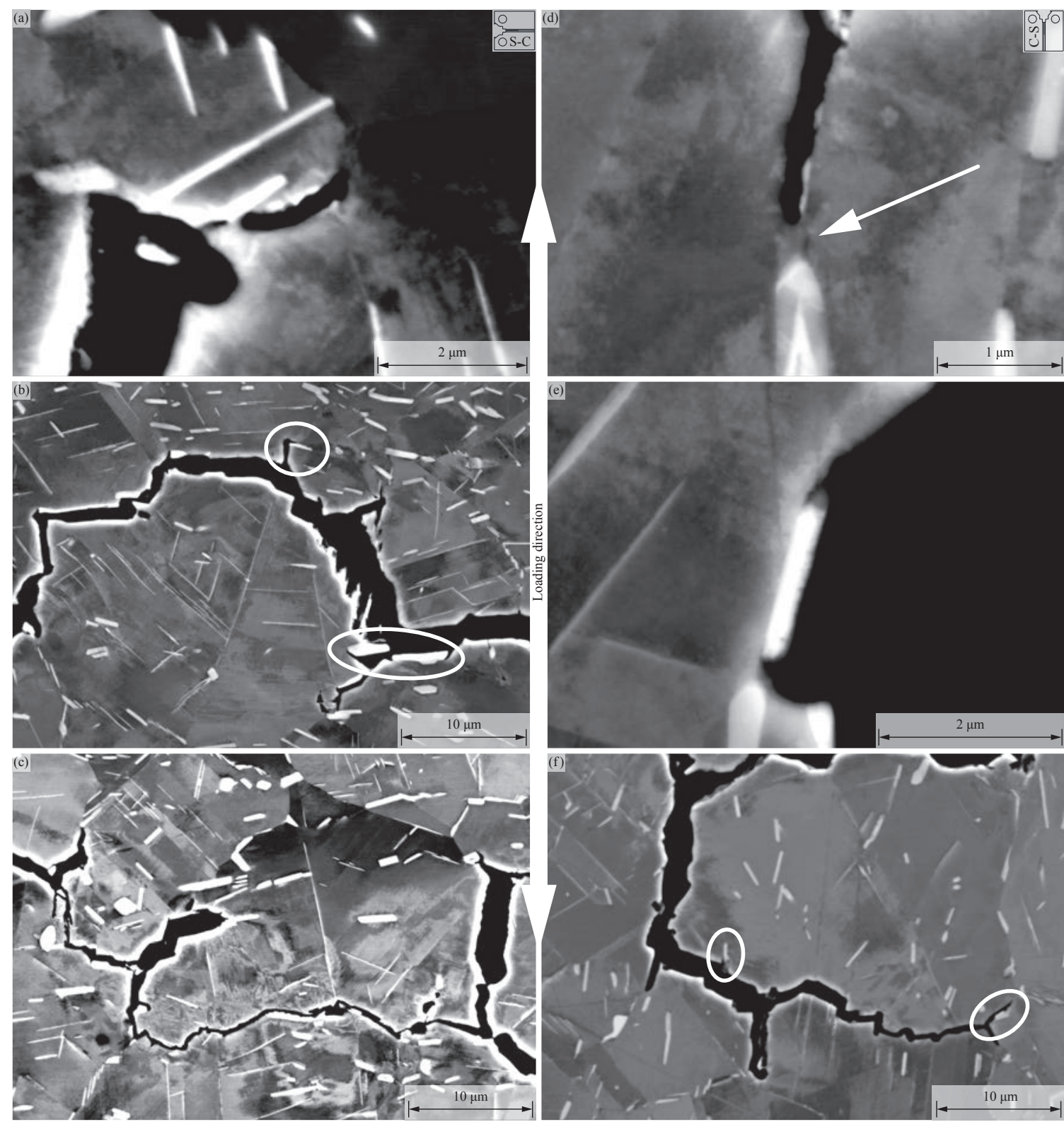

Figure 5: Cross section images of sample 3 (S-C, left column) and sample 6 (C-S, right column), a plane stress, with $90 \mathrm{~s}$ and $2160 \mathrm{~s}$ dwell-times respectively. (a) The secondary crack tip grows in the interface between the $\delta$-phase and $\gamma$-matrix. (b) Intergranular crack growth shows delamination of $\delta$-phase as well as secondary cracks grows into the interface between the $\delta$-phase and $\gamma$-matrix. (c) Plastically deformed material and slip bands. (d) The blunting effect of a secondary crack tip. (e) $\delta$-phase delamination. (f) Intergranular crack growth as well as secondary cracks growing into the interface between the $\delta$-phase and $\gamma$-matrix. 